\title{
Las nuevas tecnologías de información y comu- nicación y las políticas culturales en México - Ingeniería en Comunicación Social del servicio de redes sociales Facebook
}

\author{
Jesús Galindo Cáceres*
}

\section{Resumen}

El texto presenta un panorama general sobre la situación actual del servicio de redes sociales facebook, a partir de información disponible en la web, además de la tesis básica sobre la arquitectura en el diseño de este servicio de redes sociales ha sido el centro de su éxito. También se presenta el argumento de su poder constructivo de vida social, por tanto su configuración como nuevo nicho civilizatorio. La análisis es hecha desde la perspectiva del programa de investigación en Ingeniería en Comunicación Social. Facebook es un ejemplo del poder de construcción y organización social posible en el ciberespacio. Al final se apunta lo que está sucediendo en la relación entre la construcción social desde el ciberespacio, el caso de los servicios de redes sociales y su poder constructivo, y las políticas públicas por parte del Estado, en particular el Estado Mexicano. Se perfila el caso de la promoción cultural desde las políticas públicas ante la emergencia de Facebook y otros servicios de redes sociales. El aparato público está fuera del nuevo movimiento del espacio público en Internet.

Palabras claves: Ciberespacio. Servicios de redes socials. Facebook. Políticas culturales. Ingeniería en Comunicación Social.

\footnotetext{
* Profesor y investigador en el Postgrado de la Facultad de Ciencias de la Comunicación, Benemerita Universidad Autónoma de Puebla, Puebla- México. Profesor visitante en universidades de Argentina, Brasil, Colombia, Perú, España y México desde 1975 y promotor cultural en diversos proyectos desde 1972. Doctor en Ciencias Sociales, es autor de 25 libros y más de 250 artículos publicados en América y Europa. Promotor de la Red de estudios en teoría de la comunicación (REDECOM) y del Grupo hacia una Comunicología posible (GUCOM) desde el 2003. Miembro de la Red de estudios sobre Deporte, Cultura y Sociedad desde 2006. Miembro de la Red Nacional de Promotores Culturales 3d2 desde 2007. Promotor del Programa hacia una Ingeniería en Comunicación Social desde el 2009. E-mail: arewara@yahoo.com
} 


\section{As novas tecnologias de informação e comunicação e as políticas culturais no México - Engenharia em Comunicação Social a serviço da rede social Facebook \\ Resumo}

O texto apresenta um panorama geral sobre a situação atual do serviço de redes sociais Facebook a partir de informações disponíveis na web, além da tese básica sobre como o desenho da arquitetura deste serviço de rede social tem sido o centro de seu êxito. Também apresenta o argumento de seu poder construtivo de vida social, portanto sua configuração como novo nicho civilizatório. A análise é feita a partir da perspectiva do programa de investigação em Engenharia em Comunicação Social. Facebook é um exemplo de poder de construção e organização social possível no ciberespaço. Ao final, apontamos o que está acontecendo nas relações entre a construção social do ciberespaço, no caso dos serviços de redes sociais e seu poder construtivo, a políticas públicas por parte do Estado, em particular do México. Ressaltamos o caso da promoção cultural desde as políticas públicas antes do surgimento do Facebook e outros serviços de redes sociais. $\mathrm{O}$ aparato público está fora do novo movimento do espaço público na internet.

Palavras chave: Ciberespaço. Serviços de redes sociais. Facebook, Políticas culturais. Engenharia em Comunicação Social.

\section{The new technologies of information and communication and Mexican's cultural policy - a Communicatinos Engenieering in a networking Facebook Abstract}

The text presents an overview of the current state of Facebook social networking service, based on information available on the web, besides the basic thesis of text, the architecture in the design of this social networking service has been central to its success. On the other hand it makes the case of constructive power of social life, so his own niche as a new civilization. After, propose a reading of the phenomenon from the perspective of the research programm in Communicatinos Engenieering. Facebook is an example of the power of construction and possible social organization in cyberspace. At the end, points to what is happening in the relationship between social construction in cyberspace, the case of social networking services and its constructive power, and public policies by the state, particularly the Mexican state. Outlining the case for promoting culture from public policy to the emergence of Facebook and other social networking services. The state apparatus is out of the new movement of public space on the internet.

Key words: Cyberspace. Social networking services. Facebook. Cultural policy. Social Communication Engineering. 


\section{Presentación}

E ste es un apunte sobre el Facebook, un servicio de redes sociales en la web. A través de las notas que siguen a continuación se tratará de enfatizar por lo menos dos cosas. Por una parte, que la arquitectura del ciberespacio nos está construyendo más allá de lo visible, y es necesario aprender cómo, y dirigir la atención a diversificar las figuras constructivas desde diversos, interactivos y participativos puntos de vista. Y por otra parte, que las políticas culturales asociadas a fenómenos como el Facebook, están en un nivel de coexistencia que es casi nulo, el ciberespacio está aún muy lejos de la voluntad política tradicional pre ciberespacial.

El proceso de civilización en la historia humana ha dependido de los marcos ecológicos donde se ha desarrollado. Durante siglos el clima y la localización geográfica fueron los factores centrales para la vida humana y los pequeños pasos hacia una mayor independencia de la naturaleza. Todo se transformó cuando la ciudad hizo su aparición, el gran metabolizador del cambio humano. Pero aún faltaba algo más, la aparición del ciberespacio, con el antecedente de los medios electrónicos de difusión de información. Y quizás aún falte más. Por ahora la nueva ecología emergente con su peculiar metabolismo civilizatorio e independencia de la naturaleza es el mundo digital. Y estamos ensayando a percibirla y a entenderla. Observemos y pensemos por un momento a Facebook.

\section{El fenómeno social de Facebook - Una imagen sorprendente y simple}

Nuevos tipos de redes sociales entran en escena a mediados de la primera década del siglo veintiuno. Emerge una nueva Internet a partir del correo electrónico y las listas de correos, pasando por las salas de chat, el hipernews, hasta llegar a myspace, Facebook, youtube, flickr y twitter. Existen varios tipos de nuevas redes sociales en el momento actual, redes educativas, redes profesionales, redes de innovación, redes de entretenimiento, redes ciudadanas, redes de socialización, y otras. El fenómeno está aún en emergencia y ocupando nuevos nichos de actividad a partir 
de diversos intereses y connotaciones de grupo. Pero entre todas ellas es Facebook la reina, el gran fenómeno de las redes sociales en el ciberespacio.

Las redes sociales tienen diversas definiciones. Una definición general contiene elementos que implican a las llamadas redes sociales en Internet.

- Definición general de red social en Wikipedia.- Una red social es una estructura social compuesta de personas (u organizaciones u otras entidades), las cuales están conectadas por uno o varios tipos de relaciones, tales como amistad, parentesco, intereses comunes, intercambios económicos, relaciones sexuales, o que comparten creencias, conocimiento o prestigio.

- Nota en Wikipedia.- Es importante distinguir red social o redes sociales de los "servicios de red social" como Facebook y MySpace entre otros. Las redes sociales como campo de investigación tiene unos campos de aplicación mucho más amplios que los de los "servicios de red social".

- Concepto de redes sociales en la web según la ya clásica definición de Dana Boyd y Nicole Ellison.- Servicios basados en la web que permiten a los individuos 1) construir un perfil público o semipúblico dentro de un sistema delimitado, 2) articular una lista de usuarios con los que comparten una conexión, 3) ver y recorrer su lista de conexiones y aquellas hechas por otros dentro del sistema. La naturaleza y la nomenclatura de estas conexiones puede variar de un sitio a otro.

Y dentro de este perfil general y acotado a la web, lo que sucede con Facebook impresiona. Nace en 2004, tiene en la actualidad sobre 500 millones de usuarios, más de la mitad navega todos los días. El 10 por ciento actualiza su perfil todos los días. Se suman medio millón de usuarios por día. Ha crecido 250 millones en un año. En el último año su crecimiento entre 18 y 24 años ha sido de $5 \%$, entre 25 y 34 de $60 \%$, y entre 35 y 54 de 190\%. México es el primer país de América Latina en Facebook con 12.5 millones de usuarios, la mitad mujeres.

Facebook es masivo, un alfabetizador fácil, con una arquitectura simple, una convergencia digital alta y sencilla. Promotor de un tipo de cultura de lo fácil, lo divertido, lo accesible. Facebook 
es el nicho perfecto de una nueva cultura emergente, todo en retazos, integrado en forma efímera, siempre en movimiento, sólo tocando la superficie. Una complejidad que muta todo el tiempo, que parece no concretarse en nada, que siempre está en cambio, sin sedimento, sin forma de fondo, sin profundidad alguna. Ejemplo claro de una nueva forma de la cultura contemporánea.

La participación en un sentido colectivo es baja. Es una plataforma construida hacia lo socialmente aceptable, que ha permitido el acceso masivo de los conservadores, de los tradicionales. Se centra en la subjetividad del usuario más que en intereses y conocimientos compartidos. Su cultura convergente y participativa es aún emergente. Los lazos fuertes previos al ciberespacio son los que mantienen sus redes sociales. Continuidad de la vida online de la vida offline. Reforzamiento de lazos preexistentes. Nada ha convocado a los analfabetas digitales en la forma en que lo ha hecho Facebook.

El gran secreto de su útil convergencia y el boom demográfico es la simplicidad en las habilidades necesarias para moverse en su plataforma. La comunicación de elite, de especialista, es desplazada por la interacción simple y sencilla. Facebook es masiva, democrática y simple. Los usuarios de Facebook tienen una forma de interacción básicamente lúdica, de placer. Mundo superficial, de paseo, de gozo. El voyerista que mira por el ojo de la cerradura a los demás, en silencio y con el Mouse por cómplice, y el exhibicionista que satura su muro con información casi siempre inútil, superficial, a veces entretenida.

\section{La arquitectura de Facebook, el centro de una estructura de civilización emergente}

Para observar un fenómeno parecido a un estallido, un big bang social, es necesario preguntarse qué es lo que está detrás de lo fenoménico. ¿Cuál es el secreto? En el caso de Facebook la hipótesis es que el secreto está en su arquitectura en armonía con las formas sociales no ciberculturales que se conectaron con ella. La arquitectura como fenómeno de configuración estética y social hace tiempo que tiene una certidumbre, afecta la vida social en la cual se plasma en forma material. Por extensión la racionalidad 
del diseño en todas sus áreas y fases de desarrollo tiene una configuración constructiva similar. De ahí que hablar de la importancia de la arquitectura del ciberespacio sea similar a la observación sobre el éxito del diseño de un parque público para reconfigurar las relaciones ciudadanas en un barrio urbano.

El deporte ha sido considerado como una configuración del proceso de la civilización occidental. El punto clave de esta evaluación es el movimiento hacia la complejidad que parte del control y el autocontrol, frente a la violencia y la agresividad espontánea y visceral. El deporte civiliza, el fútbol y el béisbol son parte de una onda general que mueve a la convivencia humana hacia un nicho superior de construcción de las relaciones sociales y los vínculos estructurales. Los ciudadanos pasan de ser guerreros asesinos a parlamentarios dialogantes. La cortesía y las normas del diálogo van de la mano del deporte.

El punto aquí es que la Internet también es una configuración de civilización, y en particular los servicios de redes sociales pueden ser claves en la construcción de nuevas relaciones sociales de convivencia civilizada. En ese sentido Facebook es un caso ejemplar, como el fútbol es para el deporte. La comunidad de redes sociales más grande del mundo está promoviendo la convivencia pacífica, las relaciones sociales como situaciones de intercambio de información y de afecto cuya consecuencia es una mejor estructura del movimiento social general de convivencia. Esta es la gran cuestión, las redes sociales en el ciberespacio son promotoras de la cordialidad y el diálogo pacífico. En principio la propia arquitectura del ciberespacio promueve que sea así, el software está formateado para promover relaciones pacíficas.

En este argumento la arquitectura de Facebook es el elemento central. Al ser relativamente fija y estable está permitiendo el acceso masivo y múltiple de todo tipo de personas, que de otra manera no llegarían al ciberespacio y a su marco de posibilidades. Facebook por su arquitectura accesible es un alfabetizador digital, y en ese sentido una puerta grande a la cibercultura, y en este sentido un nicho de convergencia civilizadora. En Facebook la gente convive pacíficamente, pone en escena lo mejor de sí en un sentido lúdico y armónico. La plataforma condiciona a que todo sea cordial, amable, 
simpático. Y con ello refuerza estructuras de convivencia pacífica, y por tanto civilizatoria. Por ejemplo es posible afirmar con un clic que se gusta de algo dicho o presentado por otro, pero no es posible lo contrario. La cortesía de la red.

En el software la forma hace al contenido. El comportamiento es en parte determinado por lo que permite y hace posible la arquitectura de la plataforma. Se condiciona a partir de lo básico, interfaz, contenidos, circulación de información. Forma comunidades a partir de la suma de egos, promoviendo los lazos pre-existentes. El ciberespacio es diversos espacios configurados según diversos formatos o arquitecturas. Esas arquitecturas prescriben lo que se puede y lo que no se puede hacer. Todo está regulado a partir del software, el cual prescribe conductas y comportamientos. Una imagen de arquitecturas sobrepuestas en un fenómeno único. El software del ciberespacio en relación con el software del mundo ordinario fuera del cibermundo.

Cultura de la convergencia tecnológica accesible a usuarios con poca o ninguna habilidad cibercultural. Audiencias operando de la mano de las empresas del ciberespacio. Facebook, aparece como un nuevo organizador de la red. Primero fue la lógica constructiva de Yahoo, luego la de Google, y ahora la forma constructiva de las plataformas de servicios en línea de las redes sociales. La llamada web centrífuga (Google), la que te lanza hacia fuera en la búsqueda de información, frente a la web centrípeta (Facebook), que te concentra en los lazos que ya tenías más algunos más. Y esa es la noticia, el servicio de redes sociales refuerza la comunidad social, y al mismo tiempo la enriquece. No se trata de una gran revolución de la convivencia humana como sueñan los tecnofílicos, sino de una plataforma de sociabilidad que la web no había tenido hasta hoy con esta extensión.

No todo son buenas noticias, aunque la base está ahí, y en ello consiste el reto a la imaginación constructiva hacia el futuro. Los individuos hablan de sí mismos. No hay diálogo en profundidad. Aunque rompen la norma 90-9-1, no desarrollan una gran participación. La ley 90-9-1, de cada cien usuarios, noventa sólo observan, nueve participan esporádicamente, y sólo uno propone los contenidos. Ley Nielsen. Pero en Facebook publicar es fácil, 
todos somos potenciales creadores en esta accesible plataforma. Y es sencillo expresarse, sólo basta un pequeño empujón social en la convivencia y la complicidad con los conocidos, un teclado, un Mouse, un poco de tiempo libre.

La participación masiva coincide con una aparente degradación de los contenidos. Lo popular irrumpe en Internet. Puro entretenimiento, exhibicionismo exacerbado y contenidos banales. Superficialidad y velocidad.

Más que promover nuevas relaciones, refuerza las existentes por nuevos medios. Las redes íntimas no pasan de 30 o 40 personas. Relevante la importancia del uso del nombre real. Eso promueve el contacto con el mundo pre-existente. Cuantos más vean mi vida, mejor. Presentación ficticia de la realidad. Presentación realista de una ficción. Gente reunida por lo que ya tiene en común. No se participan las diferencias. Hay seguidores, soles virtuales y linkers (propiamente participativos). Diversos roles en el nuevo entorno social virtual, el conversador, el proveedor, el promotor, el recomendador, el crítico. El mundo social de las redes en el ciberespacio se complejiza. Aumento en las formas de socialización y comunidad en el ciberespacio, a partir de las formas comunitarias pre existentes.

La red social de Facebook se configura en la forma de la comunidad. ¿Desarrolla socialización? Facebook, una agenda de conexiones sociales, frágiles, mundanas, efímeras. Los lazos parecen débiles y de paso son el centro de la configuración comunitaria de la plataforma. Los vínculos se generan y reproducen en superficie. Pero existen, se multiplican, se extienden, colonizan territorios, se van complejizando poco a poco, se desfiguran, se vuelven a configurar. Lo que ahí sucede se parece en principio a lo que pasa fuera del cieberesapcio, y en la comparación parece perder, pero hay más, mucho más, y en aumento.

\section{Una mirada Comunicológica y de Ingeniería en Comunicación Social a Facebook}

Facebook es parte de un momento en el desarrollo del ciberespacio y la cibercultura. Es quizás el momento más interesante de todos los hasta ahora vividos. El gran boom de Internet vino de 
dos figuras claves. Por una parte la necesidad de información, el acceso a sistemas de información antes cerrados, y la circulación de paquetes de información como nunca en la historia humana. Y por otro la aparición de las comunidades virtuales, que anunciaban el potencial social de esta nueva ecología hacía el futuro. Ambas figuras asociadas a sistemas de información y a sistemas de comunicación han continuado su evolución, y hoy ofrecen escenarios emergentes de proporciones fantásticas.

El ciberespacio es un escenario donde múltiples sistemas de información tienen un nuevo nicho para difundirse, a gran velocidad, con impecable fidelidad. La figura de Google es clave en esta configuración. Pero por otra parte los sistemas de comunicación han ido aumentando su metabolismo de acción en esta nueva ecología humana. Lo primero que asombraba era el contacto entre los diferentes para configurar extrañas formas de lo novedoso, de lo excéntrico, de lo innovador. Pero faltaba lo mejor, la presencia masiva de los mundos comunes y conservadores, la mayor parte del mundo fuera del ciberespacio. Esta parte del mundo había entrado poco a poco al emergente cibermundo, pero sobre todo a través de sus intereses más evidentes en lo económico, y después en lo político, faltaba la gran masa social. Y fueron los servicios de redes sociales los que permitieron lo último que faltaba. Los sistemas de comunicación ordinarios han llegado al ciberespacio.

La gran entrada mayoritaria del mundo social al ciberespacio aún no acontece, para eso faltan aún ciertas condiciones, pero lo acontecido con Facebook es un anuncio de lo que sucederá cuando eso aparezca. De ahí la importancia de observar y pensar lo que ha sucedido en esta primera década del siglo veintiuno. Una configuración por completo no natural, y no sólo humana, está en movimiento, el ciberespacio trae consigo el potencial de contacto humano más impresionante en la historia. La mediación digital cambiará al mundo por completo. Un proceso de Ingeniería Social espontáneo está en proceso, y la necesidad de una Ingeniería Social reflexiva está en la mesa.

Los procesos de dominación y colaboración en las figuras de la difusión y la interacción, desde un punto de vista comunicológico, tienen en el ciberespacio una expresión intensa y extensa. El uso 
epistemológico de la difusión y de la interacción está en curso, sólo la imaginación es el límite. Por ahora tenemos a muchos habitantes del ciberespacio, baja actividad e interactividad equivalente a la que se da fuera del cibermundo. Pero la situación está cambiando, el metabolismo de vida social de la web va en aumento, y está modificando la vida fuera de la web cada vez con mayor intensidad y extensión. Parecería que la cibercultura aporta más a la cultura individual que a la cultura convergente colectiva, pero esto no es así del todo, la colaboración y la emergencia de una cibercultura constructiva colectiva y participativa está por evolucionar en un salto hacia delante, la cultura wiki.

La difusión, sistemas de información que dominan a otros sistemas de información, sistemas sociales que ordenan a otros sistemas sociales. La arquitectura del ciberespacio está en la mira de esta configuración comunicológica. Y también es claro el intento de usos con beneficios unilaterales por parte de los ámbitos del mercado y de la política. Pero lo propio de la vida social en las plataformas de servicio de redes sociales es la interacción, el movimiento hacia la colaboración. De ahí que la incipiente generación de espacios horizontales dialógicos pueda ser percibido como el principio de algo que está por desarrollarse, por detonar a gran escala en el ciberespacio, y por tanto en todo el mundo en un sentido global. El cibermundo aún es un nicho del consumo individual, pero se va moviendo hacia un nicho de la colaboración y la construcción colectiva y participativa. De sistemas de comunicación difusión en procesos de dominación, a sistemas de comunicación interacción en procesos de colaboración.

La brecha digital. Hay gente fuera y gente adentro. La separación y la distancia tienen efectos aún difíciles de precisar o de entender. Los sistemas de comunicación fuera del ciberespacio se mantienen estables en sus propias genealogías, pero están siendo afectados por los nuevos lazos virtuales. Los sistemas de comunicación mixtos, mundo- cibermundo, son impredecibles por el momento en su desarrollo y complejización. Los que quedan afuera parecen permanecen sujetos a los hilos culturales del pasado, los que estaban dentro antes del boom de las redes sociales parecen iniciar nuevas genealogías. Las relaciones entre el dentro y el 
afuera en emergencia están mutando las primeras claridades. Los sistemas de comunicación social tienden a la mediación estructural por el ciberespacio, cada vez más interacciones en el mundo están mediadas por el cibermundo, el hipermundo, el mundo mixto, se configura como el mundo del futuro.

La intención constructiva se mueve por todas partes en el ciberespacio, toma la figura del negocio, de la propaganda, del proselitismo. Está en marcha una Ingeniería en Comunicación Social para la difusión, para la dominación. Esta es una herencia clara de las genealogías preponderantes de construcción de la vida social previas al ciberespacio. Pero también hay la otra Ingeniería en Comunicación Social, la que va construyendo entre todos los participantes el nuevo fenómeno de interacción global, la colaboración por redes horizontales de la nueva vida cotidiana. Las dos Ingenierías en Comunicación Social están en marcha, y van apareciendo los protagonistas de ambos movimientos. En algunos puntos se encuentran, en otros chocan.

Las instituciones sociales en general están en el pasado, son previas al ciberespacio, como las instituciones que portan el poder constructivo de las políticas culturales. Hay rutas paralelas separadas entre el cibermundo y el mundo, por una parte convergencia, por otra parte distancia. Todo un fenómeno de nueva segregación, marginalidad, diferencia, movilidad. El hipermundo existe, el mundo mixto, gana espacio, pero también aprende a convivir con sectores segregados del cibermundo. Es decir, se empieza a estabilizar cierta configuración convergente al mismo tiempo que cierta configuración divergente. Por una parte mundo y cibermundo se acercan, y por otra parte aparecen nuevos muros y fronteras que los separan. Todo un tema para la Comunicología y la Ingeniería en Comunicación Social. Todo está moviéndose muy rápido y acomodándose de nuevo. La percepción empoderada es clave, y más urgente la intervención empoderada. Urge el desarrollo de una Comunicología y una Ingeniería en Comunicación Social del ciberespacio y del hipermundo, el mundo mixto. Tareas urgentes, imprescindibles, y no podemos esperar al campo académico ni a los políticos tradicionales para desarrollarlas. 


\section{Las políticas culturales y las nuevas tecnologías de información y comunicación - El caso Facebook y los servicios de redes sociales en la web}

Tenemos de entrada un conflicto, una distancia, una separación, entre Políticas públicas y políticas privadas sobre cultura. El Facebook pertenece al mundo de lo privado dentro de un nuevo espacio público. La mirada tradicional pública observa al espacio público tradicional, no percibe a este nuevo espacio público. $\mathrm{Pa}$ recería que al nombrar al ciberespacio y al mundo cotidiano fuera del ciberespacio estamos hablando de dos entidades por completo diferentes. En el caso mexicano el asunto se agrava, la genealogía de la vida social ciberespacial ha ido por fuera de la vida social mayoritaria. Pero la brecha se acorta, las fronteras se adelgazan. En lo que todo esto sucede el gobierno se entera poco y sólo empieza a balbucear sus primeros pasos en la construcción social de la web. Web y gobierno mexicano son dos configuraciones distantes y diferentes casi incomunicadas por completo.

Hay un movimiento social que no se ve en las calles, tiene otra cultura, y se ha despegado del mundo de las instituciones políticas públicas tradicionales. La cibercultura silvestre es muy diversa de la cultura tradicional. Sobre todo en dos punto, la diversión y la autonomía de lo real y sus sanciones. Poco que hacer en este momento desde el espacio público oficial, lo que tiene enfrente es una cosmología que lo rebasa, que le es casi invisible, e incomprensible.

El Facebook ya no es de vanguardias innovadoras que colonizan el nuevo territorio del ciberespacio, es de públicos masivos transclasistas y transgeneracionales, un fenómeno de cultura popular emergente. El Facebook es lúdico e incontrolable más allá de la arquitectura, de la plataforma, que tiene intereses comerciales que viven de la intención de entretenimiento de las redes sociales a las que les dan servicio. Todo esto daría una oportunidad a la cultura política hegemónica, que también es conservadora y tradicional, al tiempo que ocupada en sus propios intereses. Pero no está sucediendo así.

Es posible pensar diversos tipos de redes sociales por grupos y especialistas, pero las redes sociales en el ciberespacio en principio 
son configuraciones individualistas, egoístas, hedonistas. La política pública tradicional tiene un reto con este nuevo frente de trabajo. La cultura política tradicional está acostumbrada a tener el control, a manipular desde su punto de vista, a tener los elementos de dominio ecológico, a negociar con los escépticos o adversos a través de regalos o concesiones. El habitante del ciberespacio se encuentra con grados de libertad a los que la política tradicional no está acostumbrada. Para empezar tiene que aprender y participar en un ámbito que le es ajeno, del cual no tiene referentes claros dentro de su propia genealogía. Y por otra parte no tiene el control, lo que es por completo un reto en principio insuperable.

Quizás el escenario más extremo es el de que existe una nueva política en movimiento que puede desarrollarse desde este nuevo frente, y terminará diluyendo a la anterior. La política cultural tradicional está por completo ajena a la cultura emergente del ciberespacio y los servicios de redes sociales del tipo Facebook. Hay dos políticas, una actual, la real. Y otra que se está empezando a configurar en el ciberespacio. Acá unos cuantos tienen el poder y saben cómo ejercerlo, aunque no siempre sean impecables. Allá son muchos los que tienen el poder, y son diversos. No es el mejor escenario para políticos comunes. Incluso habría que pensar que lo que sucede como organización social y orden en el ciberespacio no es política en el sentido tradicional, es otra cosa. Lo que hay de común entre el mundo y el cibermundo es la lógica de las arquitecturas que prescriben comportamientos, por ahí puede haber una ventana de oportunidad y el punto de contacto.

Importante es la búsqueda y reconocimiento de los principios constructivos presentes en lo aparentemente nuevo, y que tienen una configuración sincrónica con formas del pasado. Como en el caso de deporte, que tiene una forma contemporánea construida en la figura del espectáculo, pero que sociogenéticamente está configurada como una forma del proceso de civilización forjador de ciudadanos, al mismo tiempo y en armonía con las figuras del parlamento y la cultura de la cortesía. ¿Qué sería lo equivalente al deporte en el caso de Facebook? Algo que sea parte del proceso civilizatorio o algo así, que ya esté ahí, y pueda ser retomado por la promoción cultural para formar ciudadanos. ¿En el caso del 
ciberespacio? Parece que la figura pre moderna de la comunidad es clave, como lo muestra la configuración de Facebook, que escenifica comunidades anteriores al ciberespacio, que se constituye a partir de las redes sociales pre-existentes al cibermundo y el servicio de redes sociales. Parece que la figura de la comunidad es otra clave para la vieja política, para su Ingeniería Social a través de canales de comunicación difusión, los que conoce y cree dominar. Tendrá que aprender a moverse en los otros canales, los de interacción-colaboración.

La cibercultura puede ser percibida como una nueva cultura, pero no sabemos bien cómo está organizada. El cibermundo es una nueva ecología, pero aún no sabemos bien hacia dónde evoluciona ni en qué consiste. No se puede conocer a esta nueva ecología y cultura sin participar. Hay que observarla desde dentro, en interacción con sus parámetros en proceso constructivo. Ya existen una multitud de experiencias que están registradas en el mismo ciberespacio. Ese un buen referente por el cual empezar a entender y descifrar lo que va configurándose en su propia e incomprensible lógica, dentro de las limitaciones y determinaciones de las arquitecturas del ciberespacio. Quizás los conceptos mismos de cultura y ecología no estén a la altura, hay que reconceptualizar, o inventar nuevos conceptos. La figura de las políticas culturales están ante la necesidad de reconceptualizarse, de volverse a entender, y de hacerlo en tanto que forman parte de la nueva cultura y la nueva ecología, aprendiendo, rehaciéndose en el contacto con arquitecturas que les son ajenas, y sobre las cuales tiene poco o ningún control, como el caso del Facebook.

Las experiencias son claves, y los que las han tenido son el centro de un proceso de generación de un nuevo tiempo espacio social. Enfrente tenemos un mundo que va en otro ritmo, con trayectorias que vienen del pasado y que se mueven en forma paralela a todo este nuevo cosmos emergente. Esta distancia es un tema en sí mismo. El mundo del ciberespacio se ha desarrollado en procesos tales que es difícil llevarle el ritmo de acción y la percepción correspondiente en el conocimiento. A los políticos de la acción cultural les viene bien conversar, y sobre todo escuchar. Los habitantes del ciberespacio, los nuevos ciudadanos, tienen 
mucho que decir, mucho que enseñar, mucho que proponerles para cambiar.

El conocimiento de la nueva ecología y cultura tiene un metabolismo rápido hacia dentro, pero un metabolismo lento hacia fuera, hacia el mundo no ciberespacial. Hacia dentro todo sucede a gran velocidad, todo se va sincronizando en formas inestables y plásticas, dentro de arquitecturas rígidas o semi rígidas. Se autoorganiza. En tanto la percepción desde el exterior no se entera, lo que sucede dentro es un universo cerrado a su entendimiento y comprensión. Esta distancia e incomunicación es muy importante. Mientras suceden cosas en el ciberespacio, el mundo exterior sigue su propio movimiento sin darse cuenta. Las relaciones entre mundo y cibermundo están aún por ser identificadas, descritas y explicadas. El punto es que imaginar al cibermundo desde el mundo no tiene efectividad en este momento, si es que alguna vez la tuvo. Y ese es el lugar de las instituciones que promueven las actuales políticas culturales en nuestro país, están fuera, en ese sentido no se enteran, no saben, son torpes, actúan a ciegas en el ciberespacio. Su Ingeniería Social es ineficiente para una configuración social distinta a la que están acostumbradas. Aún así siguen ensayando viejas operaciones para nuevos entornos.

El ámbito de la política tradicional es uno de los sectores que con más claridad están lejos de la dinámica ciberespacial. Su cosmología pertenece a otro Holón epistémico, proveniente del siglo diecinueve en gran parte. El cibermundo en emergencia crece y no está conectado con nuestras instituciones políticas, que viven aún en una exterioridad ignorante y en ocasiones arrogante. El ámbito de la economía parece estar más cerca, los actores económicos van enterándose de las posibilidades de este nuevo espacio social, y van sacando provecho. Las instituciones culturales tradicionales también parecen estar lejos, sólo las vanguardistas de cierto tipo tienen contacto con el cibermundo, la mayoría se mueven en una lógica que aún presenta los rasgos de las políticas culturales del siglo diecinueve.

Nuestros conceptos tradicionales de cultura están adecuados a las trayectorias que vienen del pasado, no son adecuados a las emergencias actuales del ciberespacio. El concepto de cibercultura 
es una transposición de un concepto viejo a nuevos escenarios, no es un auténtico nuevo concepto del todo. Es necesario un trabajo desde esta frontera entre viejos conceptos y nuevo escenarios, entre ensayos de nuevos conceptos y movimientos complejos de relación entre escenarios viejos y escenarios nuevos. Hay que darle contenido al concepto de cibercultura, y hay que poner a evaluación el viejo concepto de cultura. La Comunicología puede ser una opción, hablar de sistemas de información y sistemas de comunicación puede ser más útil para ajustarse a los nuevos escenarios.

Existe una parte del cibermundo que tiene ideas y conceptos nuevos, pero no se está comunicando bien con el mundo no cibercultural. En ocasiones parece que no tienen mucho que decir, en ocasiones parece que lo que tienen que decir no lo pueden comunicar. No es claro, pero parece que si existe una brecha entre el viejo mundo y el nuevo mundo, y no sólo en las prácticas y cosmovisiones asociadas a esas prácticas cotidianas, sino también en la inteligencia que percibe y reflexiona sobre lo que está pasando. E incluso en el lenguaje y las formas de expresión y ritualización. Tenemos un problema de comunicación de ida y vuelta. El gran peligro es que la llamada brecha digital se ensanche tanto que llegado un punto sea muy complicada, muy costosa, poco probable, la comunicación entre el mundo y el cibermundo.

¿Políticas culturales y nuevas tecnologías? Es necesario algo más que el concepto de NTIC, que no tiene sentido como concepto, es una reducción, una generalización, que casi no dice nada. Y por el otro lado, las políticas culturales están asociadas al Estado, al gobierno, y el ámbito de la cultura política oficial está muy lejos de la cibercultura. Por tanto esta relación es un proyecto, un apunte hacia un programa de trabajo, no expresa aún ningún contenido. Y en el caso de los servicios de redes sociales y políticas públicas, lo que tenemos es sólo experimentos, ensayos, no hay suficiente información aún para sistematizar, ni conocimiento para construir prospectivas. Algo hay, pero las tareas hacia el futuro parecen muy grandes y sin protagonistas competentes desde la esfera pública de la política y la acción cultural.

Las nuevas tecnologías de información y comunicación son más que un susto, una sorpresa, un rollo extraño. Necesitan un 
esquema de percepción, un programa de estudio y de experimentación. Necesitan observatorios que provean de la información suficiente para sistematizar. Necesitan entornos de interacción horizontales que están muy lejos de los usos y costumbres de las políticas culturales tradicionales. Necesitan laboratorios de experimentación social en campo, en el propio ciberespacio. Inteligencia que observe y sistematice, que escuche, que estudie, que aprenda, que proponga, que participe.

Las políticas culturales dependen en principio del Estado, del gobierno, y ese ámbito está lejos de la emergencia social del ciberespacio. Parece que algo tiene que morir para que algo crezca. Y ese escenario se relaciona con otro más probable, que lo que puede crecer no crecerá, y lo que podría morir no morirá. Es decir, la episteme y la configuración institucional de las actuales políticas culturales viene de una estructura de sociedad de información vertical y autoritaria, de dominación, el cosmos del ciberespacio horizontal y civil le es por completo ajeno. Esto supone una tensión, una tensión que puede resolverse en principio en dos escenarios, lo nuevo reconfigura a lo viejo, o lo viejo reconfigura a lo nuevo. En el caso particular de las políticas culturales lo más probable es que lo viejo insista en configurar a lo nuevo, y que lo nuevo se desarrolle fuera de su ámbito de acción. Las políticas culturales no están configuradas para entender a las nuevas tecnologías de información y comunicación más que en forma vertical, así las usarán, así obtendrán algunos resultados. Y mientras tanto otro mundo seguirá emergiendo y desarrollándose sin su complicidad. En el futuro los dos mundos se encontrarán. En un escenario uno de ellos desplazará al otro, en otro se relacionarán de alguna manera, en otro más, el viejo mundo simplemente desaparecerá poco a poco sin dejar casi rastro de su existencia. La apuesta por la Ingeniería en Comunicación Social puede ser la clave para decidir estos escenarios alternos.

\section{Referencias}

ADAMS, Richard N. La red de la expansión humana. México: Ediciones de la casa chata, 1978.

ADLER, Lomnitz, Larissa. Redes sociales, cultura y poder. México: Miguel Ángel Porrúa-FLACSO, 1994. 
AGUILAR GARCÍA, Teresa. Ontología Cyborg. El cuerpo en la nueva sociedad tecnológica. Barcelona: Gedisa, 2008.

ANDER-EGG, Ezequiel. Repensando la investigación-acción-participativa. México: El ateneo, 1990.

ANDERSON, Benedict. Comunidades imaginadas. México: Fondo de Cultura Económica, 1993.

ANZIEU, Didier y Jaques-Yves Martin. La dinámica de los grupos pequeños. Madrid: Biblioteca Nueva, 1997.

ATTALI, Jacques. Diccionario del siglo XXI. Barcelona: Paidós, 1999.

AUNGER, Robert. El meme eléctrico. Barcelona: Paidós, 2004.

BARRET, Edward et al. Medios contextuales en la práctica cultural. Barcelona: Paidós, 1997.

BARRET, Neil. El estado de la cibernación. Barcelona: Flor del viento:, 1998.

BAUMAN, Zygmunt. Comunidad. Madrid: Siglo XXI editores, 2008.

Tusquets, 2009.

. Tiempos líquidos. Vivir en una época de incertidumbre. México:

BECK, Ulrich, A. Giddens y S. Lash. Modernización reflexiva. Política, tradición y estética en el orden social moderno. Madrid: Alianza Universidad, 2008.

BERGER, Peter; LUCKMANN, Thomas. La construcción social de la realidad. Buenos Aires: Amorrortu, 1979.

BERIAIN, Josetxo (comp.). Las consecuencias perversas de la modernidad. Barcelona: Anthropos, 2007.

BERICAT, Eduardo. La integración de los métodos cuantitativos y cualitativos en la investigación social. Barcelona: Ariel, 1998.

BICKERTON, Pauline et al. Ciberestrateg. México: Prentice Hall, 2000.

BLACKMORE, Susan. La máquina de los memes. Barcelona: Paidós, 2000.

BRIGGS J.; F. D. Peat. Espejo y Reflejo: del caos al orden. Guía ilustrada de la teoría del caos y la ciencia de la totalidad. Barcelona: Gedisa, 1990.

CÁCERES, María Dolores. Introducción a la comunicación interpersonal. Madrid: Síntesis, 2003.

CEBRIAN, Juan Luís. La red. Madrid: Taurus, 1998. 
CIMADEVILLA, Gustavo. Dominios. Crítica a la razón intervencionista, la comunicación y el desarrollo sustentable. Buenos Aires: Prometeo Libros, 2004.

CUÉLlAR Ramírez, Alfredo. Genes y Memes. México: Ediciones Taller Abierto, 2004.

DABAS, Elina y Denise Najmanovich (compiladoras). Redes. El lenguaje de los vínculos. Buenos Aires: Paidós, 1995.

DE KERCKHOVE, Derrick. Inteligencias en conexión. Barcelona: Gedisa, 1999.

ELIAS, Norbert ; DUNNING, Eric. Deporte y ocio en el proceso de la civilización. México: Fondo de Cultura Económica, 1995.

ESCANDELL Vidal, M. Victoria. Introducción a la Pragmática. Barcelona: Anthropos-UNED, 1993.

FALS-BORDA, Orlando. El problema de cómo investigar la realidad para transformar la praxis. Bogotá: Tercer mundo, 1990.

FERNÁNDEZ-ARMESTO, Felipe. Civilizaciones. Bogotá: Taurus, 2002.

FERNÁNDEZ, Carmen Beatriz. Ciberpolítica. ¿Cómo usamos las tecnologías digitales en la política latinoamericana? Buenos Aires: Konrad Adenauer Stiftung, 2008.

GALINDO CÁCERES, Luis Jesús. Hacia una comunicología posible. Universidad Autónoma de San Luis Potosí: San Luis Potosí, 2005.

GARCÍA CANCLINI, Néstor; PIEDRAS FERIA, Ernesto. Las industrias culturales y el desarrollo de México. México: Siglo XXI- FLACSO- SER, 2006.

GERGEN, Kenneth J. Realidades y relaciones. Barcelona: Paidós, 1996.

GIL MENDIETA, Jorge; SCHMIDT; Samuel (Edits.). Análisis de redes. México: IIMAS-UNAM:, 2002.

HACKING, Ian. Representar e intervenir. Paidós-UNAM: México, 1996.

ISLAS, Octavio; GUTIÉRREZ, Fernando (Edits.). Internet: el medio inteligente. CECSA: México, 2000.

JOHNSON, Steven. Sistemas emergentes. Madrid: Turner-Fondo de Cultura Económica, 2003. 
LAMO DE ESPINOSA, Emilio ; RODRÍGUEZ IBÁÑEZ, José E. (Edits.). Problemas de teoría social contemporánea. Madrid: CIS, 1993.

LÉVY, Pierre. Cibercultura. La cultura de la sociedad digital. México: Antrhopos y Universidad Autónoma Metropolitana Iztapala, 2007.

LI, Charlene; BERNOFF, Josh. El mundo Groundswell. Cómo aprovechar los movimientos sociales espontáneos de la Red. Barcelona: Ediciones Urano, 2008.

MACÍAS, Norma y Diana Cardona. Comunicometodología. México: UIC, 2007.

MARC, Edmond y Dominique Picard. La interacción social. Barcelona: Paidós, 1992.

MARCUELLO Servós, Chaime (compilador). Sociocibernética. Lineamientos de un Paradigma. Zaragoza: Institución Fernando el católico, 2006.

MARISCAL Orozco, José Luis (compilador). Educación y gestión cultural. Experiencias de acciones culturales en prácticas educativas. Guadalajara: UdeG Virtual, 2009.

MARTÍN Serrano, Manuel. Teoría de la comunicación. La comunicación, la vida y la sociedad. Madrid: McGraw Hill, 2007.

MASSONI, Sandra. Estrategias. Los desafíos de la comunicación en un mundo fluido. Rosario: Homo Sapiens Ediciones, 2007.

MATHIAS, Paul. La ciudad de Internet. Barcelona: Belaterra, 1998.

MATURANA, R. Humberto. La realidad: iobjetiva o construida? Barcelona: Antrhopos-UIA-ITESO, 1996.

MAYANS I Planells, Joan. Género Chat. O como la etnografía puso un pie en el ciberespacio. Barcelona: Gedisa, 2002.

MEAD, George Herber. Espíritu, persona y sociedad. Buenos Aires: Paidós, 1968.

MITCHELL, William J. E-topía. Barcelona: Gustavo Gilli, 2001.

MOLES, Abraham. Sociodinámica de la Cultura. Barcelona: Paidós, 1978.

MORRIS, Charles. Signos, lenguaje y conducta. Buenos Aires: Losada, 1962.

MOUNIER, Pierre. Los dueños de la Red. Una historia política de Internet. Madrid: Editorial Popular, 2002. 
MUÑOZ Machado, Santiago. La regulación de la red. Madrid: Taurus, 2000. NAJMANOVICH, Denise. El juego de los vínculos. Buenos Aires: Biblos, 2005. NAVARRO Cordón, Juan M. (Coord.). Perspectivas del pensamiento contemporáneo. Corrientes y Ámbitos (Dois volumes). Madrid: Editorial Síntesis, 2004.

NEIMEYER, Greg J. (Comp.). Evaluación constructivista. Barcelona: Paidós, 1996.

O’DONNELL, James. Avatares de la palabra. Del papiro al ciberespacio. Barcelona: Paidós, 2000.

ODUM, Eugene P. Ecología: bases científicas para un nuevo paradigma. Barcelona :Vedrá, 1992.

PAKMAN, Marcelo (compilador). Construcciones de la experiencia humana. Barcelona: Gedisa, 1997.

PARSONS, Talcott. La estructura de la acción social. Madrid: Guadarrama, 1968.

PÉREZ, Rafael Alberto. Estrategias de comunicación. Madrid: Ariel Comunicación, 2008.

PISCITELLI, Alejandro. Ciberculturas. Barcelona: Paidós, 1995.

RESÉNDIZ Núñez, Daniel. El rompecabezas de la ingeniería. Por qué y cómo se transforma el mundo. México: Fondo de Cultura Económica, 2008.

REYNOSO, Carlos. Complejidad y caos. Una exploración antropológica. Buenos Aires: Editorial SB, 2006.

ROBERTS, Kevin. Lovemarks. El futuro de las marcas. Barcelona: Urano, 2005.

RODRÍGUEZ, Josep A. Análisis estructural y de redes. Madrid: CIS, 1995.

ROGERS, Everett M.; SHOEMAKER, F. Floyd. La comunicación de innovaciones. México: Herrero Hermanos, 1974.

ROGERS, Everett M.; Rekha Agarwala-Rogers. La comunicación en las organizaciones. México: McGraw-Hill, 1980.

RHEINGOLD, Howard. Multitudes Inteligentes. La próxima revolución social. Barcelona: Gedisa, 2004. 
SCOLARI, Carlos. Hipermediaciones. Elementos para una teoría de la comunicación digital Interactiva. Barcelona: Gedisa, 2008.

SCHNEIDER, Eric D. y Dorion Sagan. La termodinámica de la vida. Física, cosmología, ecología y evolución. Barcelona: Tusquets, 2008.

SERRANO Santoyo, Arturo y Evelio Martínez Martínez. La brecha digital: mitos y realidades. Mexicali: UABC, 2003.

SLUZKI, Carlos. La red social. Barcelona: Gedisa, 1996.

SMITH, Alfred G. (compilador). Comunicación y cultura. Buenos Aires: Nueva Visión, 1976.

SPECK, Ross; ATTNEAVE, Carolyn. Redes familiares. Buenos Aires: Amorrortu, 1990.

TAPSCOTT, Don; WILLIAMS, Anthony D.Wikinomics. La nueva economía de las multitudes inteligentes. Barcelona: Paidós, 2007.

TONNÏES, Ferdinand. Comunidad y asociación. Barcelona: Península, 1979.

URIZ Peman, María Jesús. Personalidad, socialización y comunicación. Madrid: Libertarias-Prodhufi, 1993.

VARELA, Francisco. Conocer. Barcelona: Gedisa, 1990.

VÁZQUEZ, Ivan. Hackers. La Coruña: El Arca de papel, 2002.

VILLASANTE, Tomás R. Cuatro redes para mejor vivir (dos tomos). Buenos Aires: Lumen-Humanitas, 1998.

VON FOERSTER, Heinz. Las semillas de la cibernética. Barcelona: Gedisa, 1991.

YUS, Francisco. Ciberpragmática. El uso del lenguaje en Internet. Barcelona: Ariel Lingüística, 2001.

WATZLAWICK, Paul et al. Teoría de la comunicación humana. Buenos Aires:Tiempo Contemporáneo, 1971. 